\title{
PREVALENCE OF MODERATE AND SEVERE ANAEMIA IN CHILDREN UNDER 5 IN UNIVERSITY OF NIGERIA TEACHING HOSPITAL ENUGU, SOUTHEAST NIGERIA
}

M.D. Ughasoro, I.J. Emodi, H.U. Okafor, B.C. Ibe

Paediatrics, University of Nigeria Teaching Hospital, Enugu, Nigeria

Background and aim: More than $50 \%$ of African children are anemic. There is limited data on the prevalence of anaemia in Nigeria. The objective of this study was to determine the prevalence of moderate and severe anaemia in children under 5.

Methods: This cross-sectional study involved under 5 children seen in University of Nigeria Teaching Hospital. Standard questionnaire was used to collect data on demographic characteristics of the respondents, child's age, gender, anthropometric measurements and Packed Cell Volume.

Results: Out of 581 subjects studied, $49.2 \%$ had moderate to severe anaemia. Those with moderate anaemia were $252(43.4 \%)$ whilst those with severe anaemia were $34(5.8 \%)$. There was association between moderate and severe anaemia and children within the age range of $6-12$ months $(59.4 \%, p=0.009)$. There was no association between moderate and severe anaemia and gender $(p=0.62)$. There was no association between moderate and severe anaemia and socioeconomic status (SES) $(p=0.66)$. There is no direct association between moderate and severe anaemia and child nutritional status $(\mathrm{p}=0.12)$.

Conclusions: Prevalence of moderate and severe anaemia is high in children under 5 years. There is no gender, SES and nutritional status association with moderate and severe anaemia among these children. Thus efforts to reduce childhood anaemia especially among children under 5 should consider other factors other than SES and nutritional status.

Acknowledgement: We acknowledge the co-operation of the children who participated in this survey. We thank Dr. Ocheni S and Mr Obikeze E for their assistance. 